\title{
From sedentary and physical inactive behaviors to the Race Across America (RAAM): a case report
}

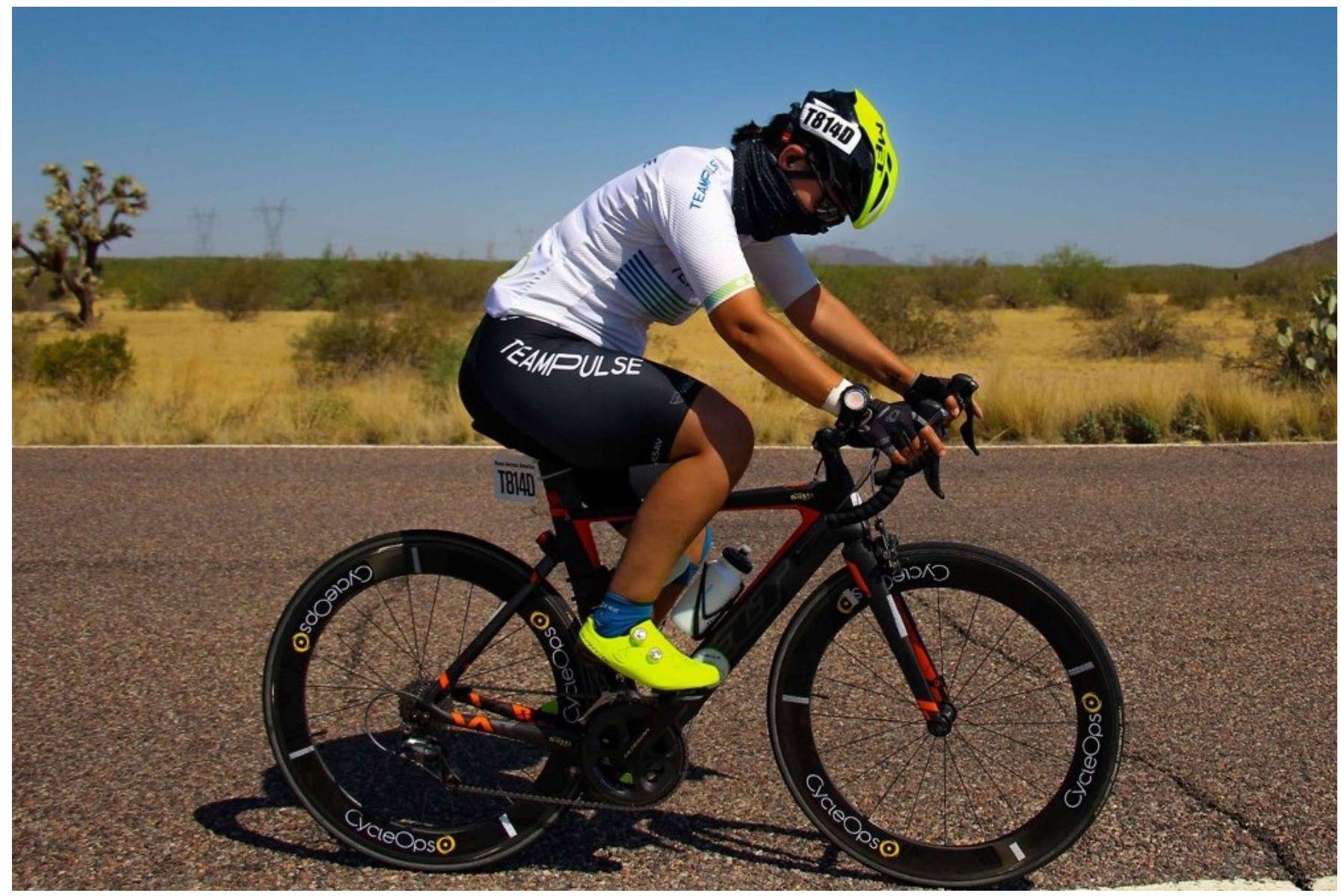

Guex K ${ }^{1}$, PhD; Besson C ${ }^{2}$, MSc; Degache F ${ }^{1}$, PhD; Gremion $G^{2}$, MD

${ }^{1}$ पSchool of Health Sciences (HESAV), HES-SO University of Applied Sciences and Arts Western Switzerland, Lausanne, Switzerland

${ }^{2}$ aDepartment of Sports Medicine, Lausanne University Hospital, Lausanne, Switzerland 


\begin{abstract}
This case report presents the evolution of physiological and psychological health parameters of a former sedentary and physically inactive nursing student during an 18 months period (three academic semesters), during which she first took part to a one-semester institutional physical activity (PA) program offered by her University, before being selected to participate in relay to the Race Across America (RAAM) with a team of the University. The four months before the RAAM, she followed a cycling specific training program. After the RAAM, she was followed-up the next eight months. Results show that each step of the study had an important impact on health parameters of the subject and that sedentary and physical inactive behaviors are not irreversible. Institutional PA program, including training education in addition to concurrent strength and endurance training could lead to physiological and psychological health improvements. Moreover, in some individuals organising a challenge might contribute to improve motivation and long-term adherence to PA participation, while in others this could have the opposite effect. An individualised approach should be considered in future interventions aiming to improve PA promotion. Finally, in the specific context of a University of Health Sciences, this kind of initiative could positively influence the general population's health, by educating students as actors in PA promotion.
\end{abstract}

\title{
Resumé
}

Cette étude de cas présente l'évolution de paramètres physiologiques et psychologiques d'une étudiante infirmière, initialement sédentaire et physiquement inactive pendant une période de 18 mois (trois semestres académiques) durant laquelle elle a d'abord participé à un programme d'activité physique (AP) proposé par son université, avant d'être sélectionnée pour participer à Race Across America (RAAM) en relais avec une équipe de l'université. Les quatre mois précédant la RAAM, elle a suivi un programme d'entraînement spécifique au cyclisme. Elle a enfin fait l'objet d'un suivi de huit mois après la RAAM. Les résultats montrent que chaque étape de l'étude a eu un impact important sur ses paramètres de santé et que l’inactivité physique ainsi que la sédentarité ne sont pas des comportements irréversibles. Un programme institutionnel d'AP comprenant une partie d'éducation à l'entraînement en plus d'entraînements combinés de la force et de l'endurance, pourrait mener à des améliorations physiologiques et psychologiques de la santé. De plus, chez certaines personnes, l'organisation d'un défi pourrait contribuer à améliorer la motivation à l'AP et son adhésion à long terme, même si chez d'autres, cela pourrait avoir l'effet inverse. Une approche individualisée devrait être envisagée dans les futures interventions visant à améliorer la promotion de l'AP. Enfin, dans le contexte spécifique d'une université des sciences de la santé, ce type d'initiative pourrait avoir une influence positive sur la santé de la population générale, en formant les étudiants à être des acteurs de la promotion de l'AP.

Mots clés: Activité physique, santé, défi, entraînement, endurance, force

\section{Introduction}

Majority of our time awake is spent being sedentary [1]. Sedentary behavior is defined as any non-sleep behavior done in a sitting, reclining or lying posture that used an energy expenditure $\leq 1.5$ metabolic equivalents (MET) [2,3]. It is well known that sedentary behavior increases the risk of many adverse health 
conditions and early mortality [4,5]. Physical inactivity is different from sedentary behavior, since it is defined as an insufficient physical activity (PA) level to meet recommendations [2,3]: at least $150 \mathrm{~min} /$ week of moderate-intensity aerobic PA, or at least $75 \mathrm{~min} /$ week of vigorous-intensity aerobic PA, or an equivalent combination of moderate- and vigorous-intensity PA [6]. Not meeting these recommendations is responsible for more than 5 million death worldwide each year [4]. Conversely, following recommendations decreases mortality risk associated with high sitting time [7]. Sedentary behavior is an important issue for University students, as they spend most of their time sitting for studying [8]. However, sedentary and physically active behaviors appear largely uncorrelated, since students could also be highly active [8,9]. In faculties of health, almost $30 \%$ of nursing students exercised less than once a week [10], leading to lower VO2max than general academic population (35.7 vs. 41.3 $\mathrm{ml} / \mathrm{kg} / \mathrm{min}$ ) [11]. Aside from being beneficial for health, PA might condition their own health behavior and their role as health-promoting actors. In fact, nurses who are more physically active and who received formal training in this field were shown to better promote PA in their clinical practice [12]. In order to improve global health outcomes for its student population, a University of Health Sciences in Switzerland developed a one-semester PA program for physically inactive students. As part of its PA promotion strategy, the University registered to participate to the Race Across America (RAAM) in team of eight cyclists nine months after the beginning of this program. The team was composed by professors and students, including a sedentary student who achieved the institutional PA program. RAAM is among the longest and most difficult ultra-endurance cycling races in the world [13,14]. It consists of cycling in one continual stage $\sim 4900 \mathrm{~km}$ from the west to the east coast.

The aim of the present case report was to present physiological and psychological health parameters of the former sedentary and physically inactive student who participated to the RAAM with the team of the University.

\section{Methods}

The case reported is a 30 years old $(168 \mathrm{~cm}, 67.9 \mathrm{~kg})$ female student in nursing sciences who took no exercise all at that time and who had never ridden a bike. The study was conducted during an 18 months period (three academic semesters) and composed by four periods (Figure 1). At the beginning of the second year of her Bachelor degree, she registered to participate to the one-semester institutional PA program offered by the University. Then, based on her adherence, progression and high degree of motivation, she was selected to integrate the team of the University for the RAAM. During the next four months, she followed the same cycling specific training program than the seven other members of the team and then took part to the RAAM. Finally, she was followed-up the next eight months. Physiological and psychological health parameters were collected prior to the beginning (T1) and at the end (T2) of the institutional PA program, directly after the cycling specific training program (T3) and the RAAM (T4). Follow-up tests were performed two (T5) and eight months (T6) after the RAAM. She was informed about the aim of the study and gave her written consent for the use of the data. All procedures were conducted according to the Declaration of Helsinki. 
weeks progressive training composed by four blocks of four weeks with 2-3 sessions/week. Each session was composed by a strength part followed by an endurance part. Strength parts contained six exercises: half-squat, bench press, leg extension, seated hamstring, rowing and lunges. Endurance parts were performed on a cycloergometer. Details on the training plan are presented in Table 1. During the last week of each block, a theoretical course on training methodology was given. Students learned how to plan their training, how to build their strength and endurance sessions, and how to monitor their training load.

\begin{tabular}{|c|c|c|c|}
\hline Block & Parameter & Strength part & Endurance part \\
\hline 1 & $\begin{array}{l}\text { Volume } \\
\text { Intensity } \\
\text { Rest }\end{array}$ & $\begin{array}{l}1-3 \times 15 \text { reps } \\
50-60 \% 1-R M \\
1 \mathrm{~min}\end{array}$ & $\begin{array}{l}30-50 \text { min } \\
40-60 \% \mathrm{MAP}- \\
70-85 \% \mathrm{MHR}\end{array}$ \\
\hline 2 & $\begin{array}{l}\text { Volume } \\
\text { Intensity } \\
\text { Rest }\end{array}$ & $\begin{array}{l}2-3 \times 10 \text { reps } \\
70-80 \% 1-R M \\
2 \mathrm{~min}\end{array}$ & $\begin{array}{l}2-6 \times 4-5 \mathrm{~min} \\
75-80 \% \mathrm{MAP}- \\
92-96 \% \mathrm{MHR} \\
4-5 \mathrm{~min}\end{array}$ \\
\hline 3 & $\begin{array}{l}\text { Volume } \\
\text { Intensity } \\
\text { Rest }\end{array}$ & $\begin{array}{l}2-3 \times 6 \text { reps } \\
85 \% 1-\mathrm{RM} \\
3 \mathrm{~min}\end{array}$ & $\begin{array}{l}2-3 \times 6-9 \times 30 \mathrm{sec} \\
100 \% \mathrm{MAP}- \\
96-100 \% \mathrm{MHR} \\
30 \mathrm{sec} / 5 \mathrm{~min}\end{array}$ \\
\hline 4 & $\begin{array}{l}\text { Volume } \\
\text { Intensity } \\
\text { Rest }\end{array}$ & $\begin{array}{l}2-3 \times 4 \text { reps } \\
90 \% 1-R M \\
3 \mathrm{~min}\end{array}$ & $\begin{array}{l}3-4 \times 4-6 \times 6 \mathrm{sec} \\
>250 \% \mathrm{MAP}- \\
90-95 \% \mathrm{MHR} \\
6 \mathrm{sec} / 5 \mathrm{~min}\end{array}$ \\
\hline
\end{tabular}

Table 1: Training plan of the institutional physical activity program for physically inactive students.

Cycling specific training program

After her selection for the RAAM, she received a racing bike and followed an 18 weeks cycling specific training program with the seven other members of the team. At that time, she had never ridden a bike outdoor. The program was composed by 3-5 sessions/week: 0-1 strength session and 3-5 bike sessions. About six weeks before the RAAM, the subject took part, during eight consecutive days to a pilgrimage, in which she walked a total of $297 \mathrm{~km}(33.0 \pm 8.3 \mathrm{~km} /$ day $)$.

\section{Race Across America}

The team finished the RAAM in 7 days $12 \mathrm{~h}$ and $46 \mathrm{~min}(25.8 \mathrm{~km} / \mathrm{h})$. The subject carried out eight relays for a total of $300 \mathrm{~km}(37.5 \pm 17.1 \mathrm{~km} /$ relay $)$ at an average speed of $26.7 \mathrm{~km} / \mathrm{h}$. She did not suffer from any disorder during the race, except following her two last relays, where she described some digestive 
disorders and pains $>30 \mathrm{~mm}$ on visual analog scale in hip-low back and cervical areas. One week after the RAAM, digestive disorders and pains had disappeared.

\section{Monitoring of workout load}

During institutional PA program, cycling specific training program and RAAM, the subject was asked to monitor her training load. For endurance parts, load corresponded to the product of the session duration and session rating of perceived exertion (RPE) [15,16]. For strength parts, it corresponded to the product of the total number of repetitions and session RPE [17-19]. The sum of both parts gave workout load. Load of each week (sum of each workout of the week) is presented in Figure 2.

\section{Follow-up period}

After the RAAM, the subject did not received training plan anymore. She was let free to continue to participate in PA or not and she was no more asked to monitor her workout load.

\section{Physiological health parameters}

Physiological health data consisted of anthropometric parameters, self-reported measure of PA, strength and endurance parameters. They were collected six times (T1-T6) during the study period (Figure 1). Anthropometric parameters (body mass index (BMI), waist-to-hip ratio (WHR), body fat mass (BFM)) were assessed using the guidelines of the American College of Sport Medicine [20]. Self-reported measure of PA was obtained using the French versions of the international PA questionnaire long form "usual week" [21]. Total PA, subtotals of walking, moderate- and vigorous-intensity PA, and estimated time spent sitting per week were reported. Quadriceps strength (QS) was measured in concentric at $60 \%$ susing an isokinetic dynamometer. Finally, to evaluate VO2max and maximal aerobic power (MAP), the subject completed a maximal intensity exercise test on a cycloergometer.

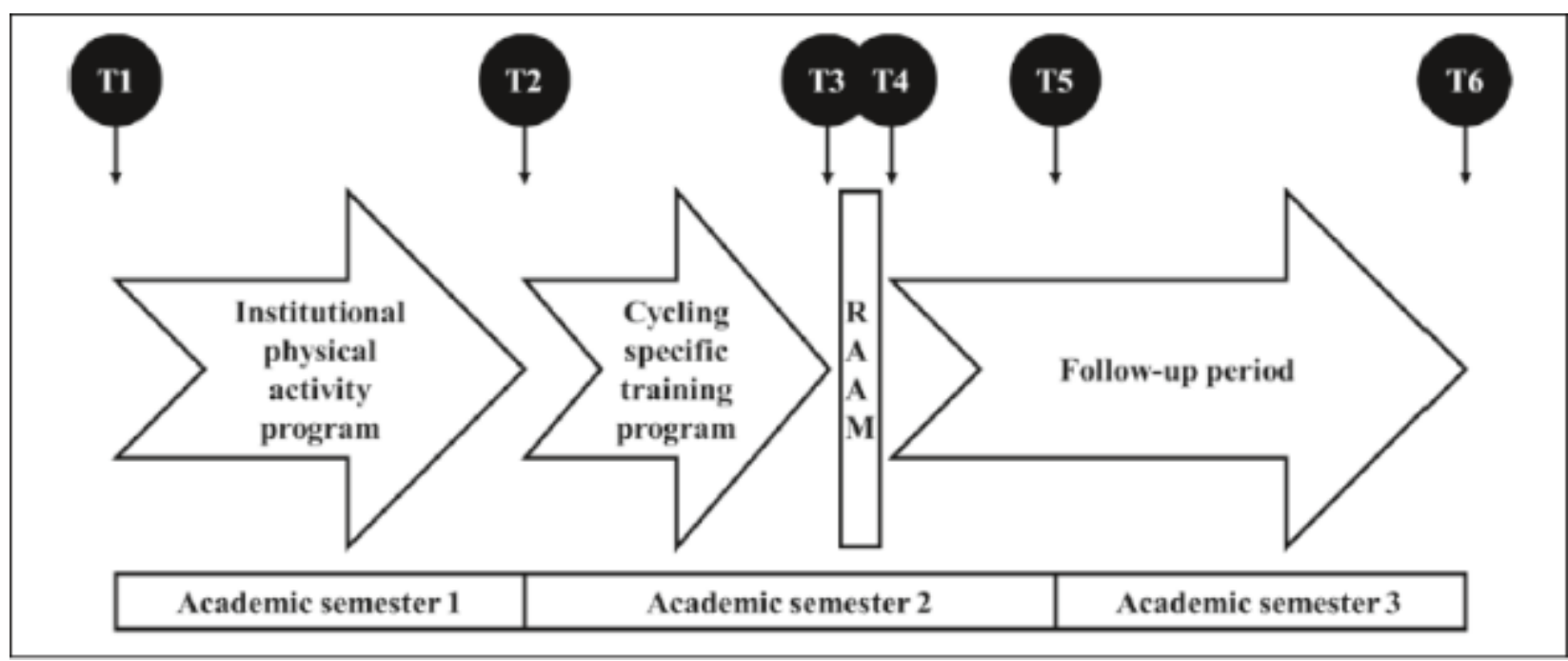

Figure 1: Four periods of the study, which was conducted during an 18 months period (three academic semesters). Physiological and psychological health parameters were collected six times over the study period

Psychological health parameters

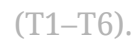


Psychological health data consisted of mood states and self-determination in sports. They were collected six times (T1-T6) during the study period (Figure 1).

To investigate the evolution of mood states during the study period, the French version of profile of mood state questionnaire was used, which measures one positive (vigour) and five negative mood states (tension, depression, anger, fatigue, confusion) [22]. Self-determination in sports was assessed using the French version of sport motivation scale, which measures three types of intrinsic motivation (IM) (IM to know, IM to accomplish, IM to experience stimulation), three types of extrinsic motivation (identified regulation, introjected regulation, external regulation) and the amotivation [23]. 

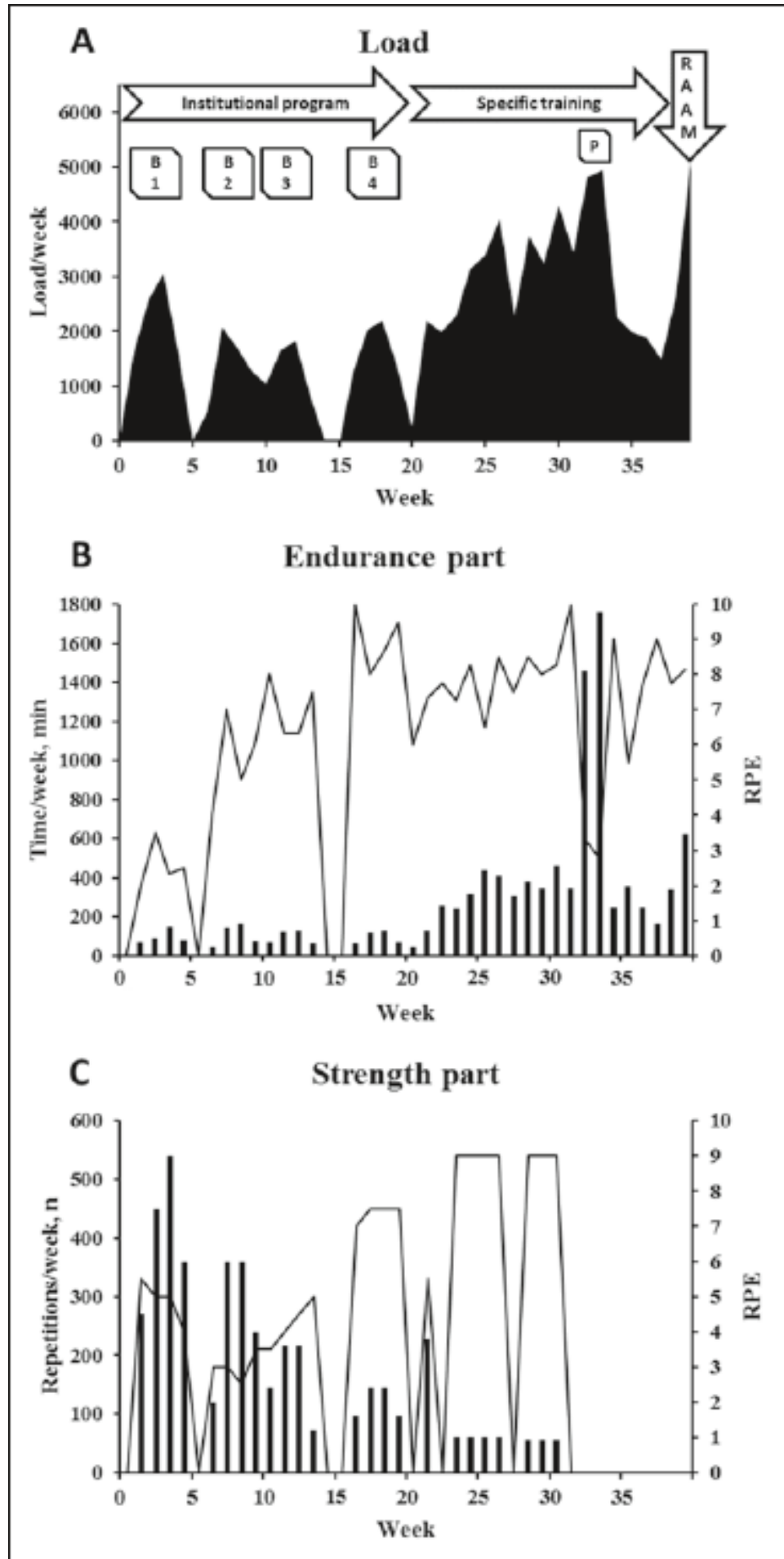

Figure 2: A, load of each week (sum of loads of each workout of the week) during the four blocks (B1-B4) of the institutional physical activity program for physically inactive students, the cycling specific training program (with the pilgrimage of eight days (P)) and the Race Across America (RAAM). B, volume (total time per week) and intensity (mean rating of perceived exertion (RPE) per week) of endurance parts. C, volume (total number of repetitions per week) and intensity (mean RPE per week) of strength parts. 


\section{Results}

\section{Physiological health parameters}

At T2, BMI increased from 24.2 to $24.8 \mathrm{~kg} / \mathrm{m} 2$, while WHR decreased from 0.75 to 0.71 and BFM remained stable from 30.2 to $30.3 \%$. At T3, BMI and WHR remained stable at $25.0 \mathrm{~kg} / \mathrm{m} 2$ and 0.72 , respectively, while BFM decreased to 29.6\%. At T4, BMI, WHR and BFM remained stable at $24.9 \mathrm{~kg} / \mathrm{m} 2,0.72$ and 29.5\%, respectively. At T5, BMI, WHR and BFM increased to $25.3 \mathrm{~kg} / \mathrm{m} 2,0.74$ and $31.0 \%$, respectively. Finally, at T6, BMI, WHR and BFM decreased to $24.5 \mathrm{~kg} / \mathrm{m} 2,0.72$ and $30.2 \%$, respectively. Evolution of anthropometric parameters is presented in Figure 3.

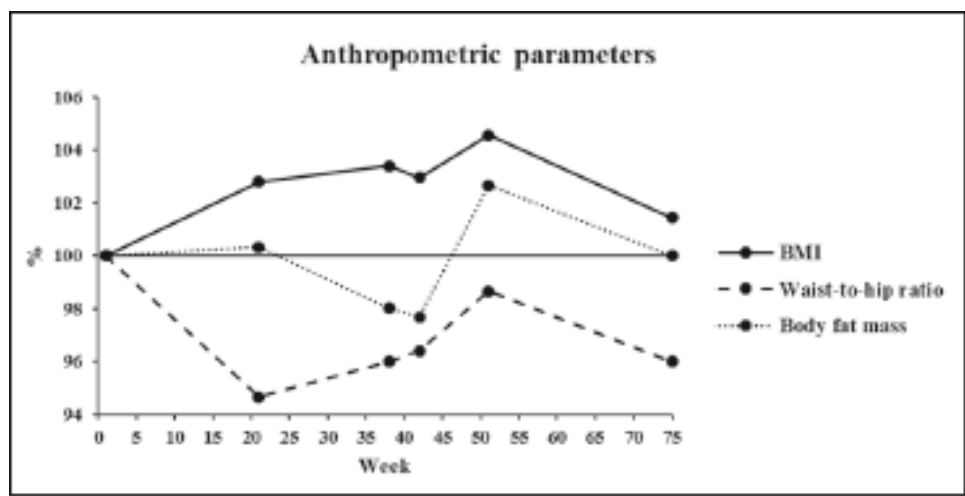

Figure 3: Evolution of anthropometric parameters during the 18 months period of the study. BMI, body mass index.

At T1, a total PA of 83 MET-min/week (composed by walking activities solely) and a sitting time of 3360 $\mathrm{min} /$ week were reported. At T2, total PA increased to 4329 MET-min/week (composed at 50\%, 48\% and 2\% by vigorous-intensity, walking and moderate-intensity activities, respectively) and sitting time decreased to $2940 \mathrm{~min} /$ week. At T3 (excluding the pilgrimage period), total PA increased to 5796 MET-min/week (composed at 50\%, 26\% and $24 \%$ by vigorous-intensity, moderate-intensity and walking activities, respectively), while sitting time decreased to $1560 \mathrm{~min} /$ week. At T4, total PA and sitting time peaked at 6720 MET-min/week (composed by vigorous-intensity activities solely) and $4200 \mathrm{~min} /$ week, respectively. At T5, total PA decreased to 5043 MET-min/week (composed at 53\%, 33\% and 14\% by walking, moderate-intensity and vigorous-intensity activities, respectively), while sitting time decreased to $3300 \mathrm{~min} / \mathrm{week}$. Finally, At T6, total PA decreased to 3396 MET-min/week (composed at 56\%, 41\% and 3\% by vigorous-intensity, walking and moderate-intensity activities, respectively), while sitting time decreased to $2220 \mathrm{~min} /$ week. Results of selfreported measure of PA are presented in Figure 4. 


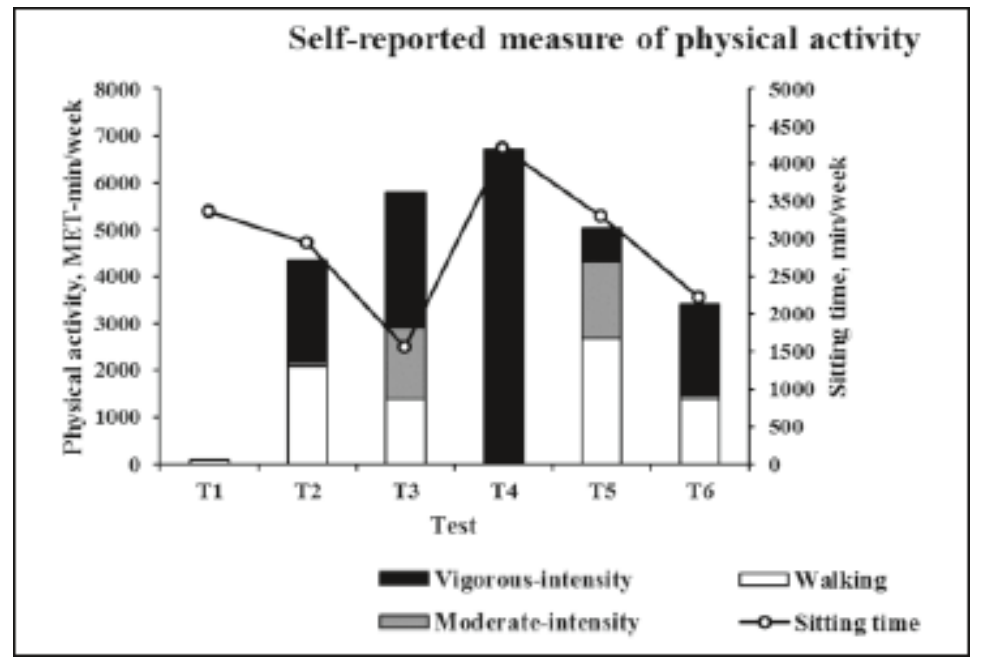

Figure 4: Self-reported measure of physical activity (PA) during a usual week before the six test times (T1-T6). Total PA is composed by walking, moderate-intensity and vigorousintensity PA.

At T2, QS, VO2max and MAP increased from 1.30 to $1.68 \mathrm{Nm} / \mathrm{kg}$, from 29.2 to $33.9 \mathrm{ml} / \mathrm{min} / \mathrm{kg}$ and from 1.91 to $2.36 \mathrm{~W} / \mathrm{kg}$, respectively. At T3, VO2max and MAP increased to $37.8 \mathrm{ml} / \mathrm{min} / \mathrm{kg}$ and to $2.85 \mathrm{~W} / \mathrm{kg}$, respectively, while QS decreased to $1.57 \mathrm{Nm} / \mathrm{kg}$. At T4, VO2max decreased to $35.0 \mathrm{ml} / \mathrm{min} / \mathrm{kg}$ and MAP remained stable at $2.86 \mathrm{~W} / \mathrm{kg}$. For logistical reasons, QS was not tested. At T5, VO2max and MAP increased to $38.1 \mathrm{ml} / \mathrm{min} / \mathrm{kg}$ and to $2.89 \mathrm{~W} / \mathrm{kg}$, respectively, while QS remained stable at $1.56 \mathrm{Nm} / \mathrm{kg}$. Finally, at T6, VO2max and MAP decreased to $35.0 \mathrm{ml} / \mathrm{min} / \mathrm{kg}$ and to $2.38 \mathrm{~W} / \mathrm{kg}$, respectively, while QS increased to 1.65 $\mathrm{Nm} / \mathrm{kg}$. Evolution of strength and endurance parameters is presented in Figure 5.

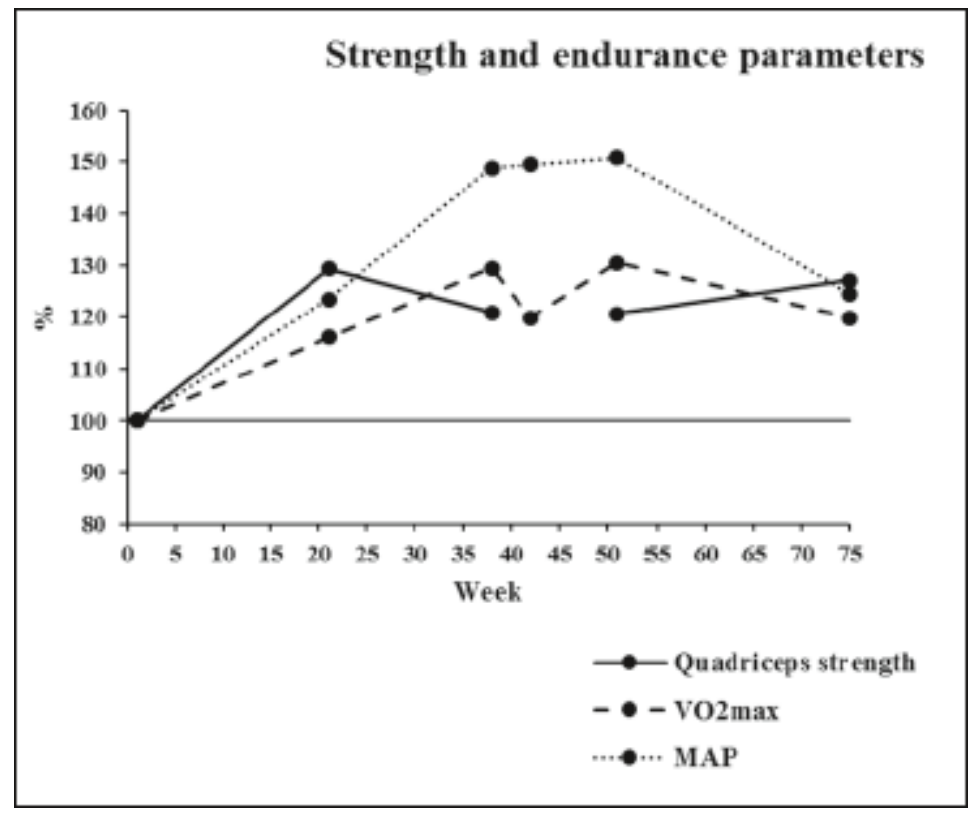

Figure 5: Evolution of strength and endurance parameters (quadriceps strength, VO2max and maximal aerobic power) of 


\section{Psychological health parameters}

During the whole study period, the five negative mood states remained low and stable. Only fatigue increased from 3 to 9 points at T4. The positive mood state remained high during the whole study period. It increased progressively at T2 and T3 from 23 to 26 and to 28 points, respectively. Results of mood states are presented in Figure 6.

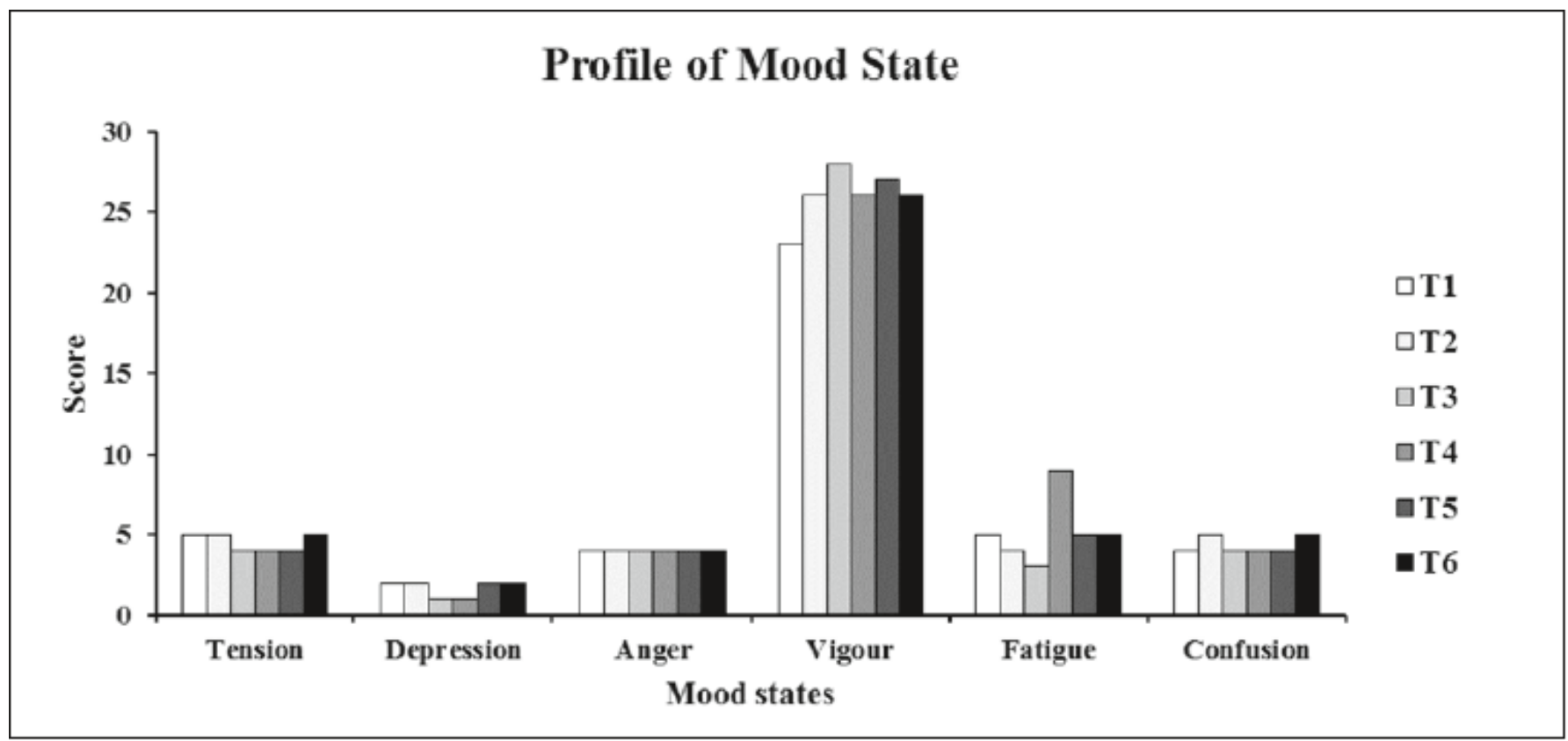

Figure 6: Results of mood states at the six test times (T1-T6).

At T2, IM to know, IM to accomplish, and IM to experience stimulation increased from 18, 16 and 9 to 25, 26 and 20 points, respectively. Identified and introjected regulation remained stable from 19 and 23 to 19 and 22 points, respectively, while external regulation and amotivation decreased from 9 and 13 to 4 and 5 points, respectively. At T3, intrinsic motivation, extrinsic motivation and amotivation remained stable. At T4, IM to know, IM to accomplish, IM to experience stimulation and identified regulation peaked at 28 points, while introjected regulation, external regulation and amotivation remained stable at 24, 4 and 4 points, respectively. At T5, IM to know, IM to accomplish, IM to experience stimulation and identified regulation decreased to 21, 25, 18 and 19 points, respectively. Introjected regulation increased to 27 points, while external regulation and amotivation remained stable at 4 points. Finally, At T6, intrinsic motivation, extrinsic motivation and amotivation remained stable. Results of self-determination in sports are presented in Figure 7. 


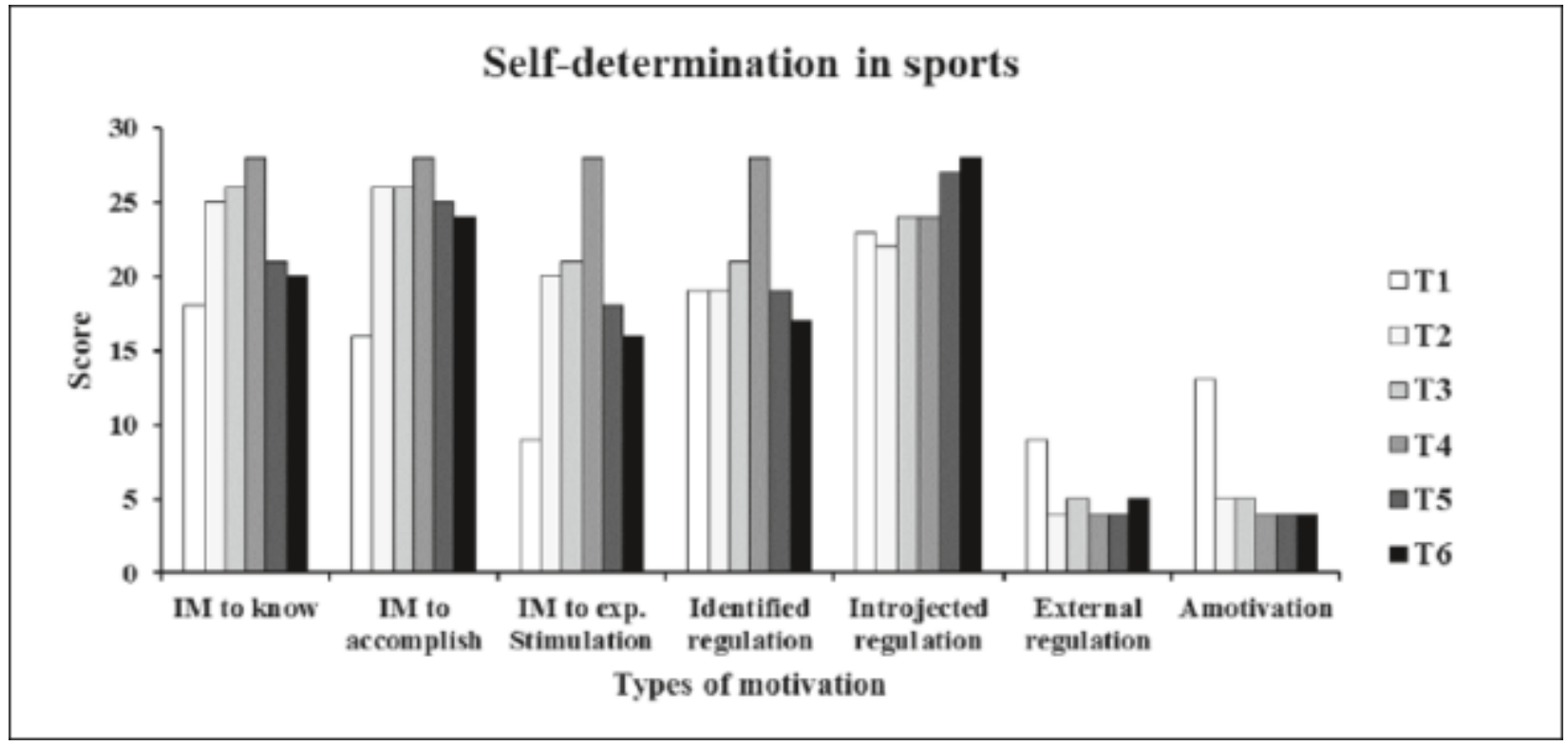

Figure 7: Results of self-determination in sports at the six test times (T1-T6). IM, intrinsic motivation; exp., experience.

\section{Discussion}

The aim of this case report was to present physiological and psychological health parameters of a former sedentary and physically inactive student, who participated to the RAAM in a team of eight and who was followed-up the next eight months. Results show that the four periods of the study had an important impact on health parameters of the subject. Each period is discussed in the following sections.

\section{Institutional PA program for physically inactive students}

Even if she still spent a lot of time sitting during this period, her level of PA largely increased, reaching two times the mean total weekly PA observed in the European Union [24]. This was accompanied by large improvements in strength and endurance parameters, in line with previous results on concurrent strength and endurance training [25]. Before the program, her VO2max was lower than previously observed in sedentary nursing students [11]. Following the institutional program, it increased to the same level. Regarding the anthropometric parameters, BMI slightly increased, while WHR decreased. This result is interesting, since WHR was shown to have higher association with myocardial infarction risk than BMI [26]. Finally, intrinsic motivations to participate in sport largely increased during this period, while external regulation and amotivation decreased, leading to a possible behavior change [27].

Responses to exercise training are not consistent among all individuals: some respond well (as it is the case in this report) and others respond poorly. Age, sex, and ethnic origin do not appear to be major determinants of responses to exercise training, while genetic background is a strong contributor to interindividual variation [28-30]. One key question is whether the response pattern in a given individual is specific to the given exercise mode and regimen [30]. This interrogation makes complicated to individualise training protocols. However, it is interesting to note that, regardless of adherence to PA guidelines, PA patterns characterized by only 1 or 2 sessions/week of moderate or vigorous-intensity PA may be sufficient to reduce risks for all-cause, cardiovascular disease and cancer mortality [31]. Finally, 
the "risk paradox" of exercise must be discussed. Despite long-standing participation in vigorous-intensity PA is associated with risk reduction of morbidity and mortality, each training session acutely increases the risk of nonfatal cardiovascular event or sudden cardiac death [32]. Even, if the proportion of myocardial infarctions linked to physical exertion is very low (especially in healthy adults and adolescents), a preparticipation exercise testing in individuals considered to be at moderate risk is recommended [20]. It is relevant to note that the latter could already elicit substantial improvements with low-intensity PA [32]. The present program was developed in the University of Health Sciences to increase PA promotion during the academic curricula. From the students' point of view, to facilitate the participation and adherence to this kind of program, it is essential to consider its accessibility, flexibility and price [33]. The proposed program was cost free, trainings were performed in flexible hours in the main building of the University and the schedule was based on the academic curricula, leading to a high participation rate (97\%) of the subject. The latter comes from the largest group of health providers: the nurses. This program may be relevant to condition their health behavior and their role as health-promoting actors, since it was shown that nurses who are more physically active and who received formal training in this field better promote PA in their clinical practice [12].

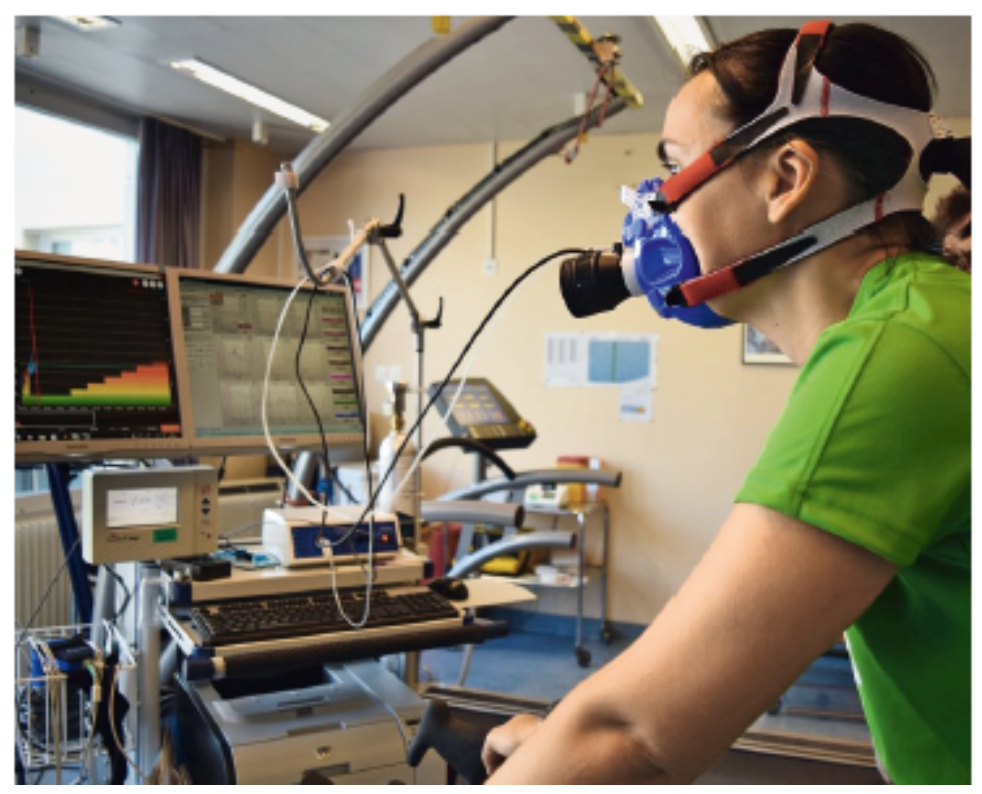

\section{Cycling specific training program}

Following this period, stabilisation in strength and linear improvement in endurance parameters (10\% higher than sedentary nursing students [11]) were observed, while only low modifications were observed over the other tested parameters. Trainings were more specific to cycling during this period. However, since the subject had never ridden a bike outdoor, she had first to learn technical aspects before being able to ride safely. Following this learning phase, she participated to all planned training sessions, leading to an increased weekly PA.

Race Across America

Even if she only made $6 \%$ of RAAM distance versus $>13 \%$ for the rest of the team, the subject did it at 
about the same speed than her teammates without major health issue. She reached her highest intrinsic motivation during the RAAM. This may lead to hypothesise that, in some individuals, a well prepared sport challenge might contribute to improve long-term adherence to PA participation, while in others this could have the opposite effect. An individualised approach should be considered in future interventions aiming to improve PA promotion. Finally, during the RAAM, she reached her highest level of PA but also her highest sitting time. This could be frequent in individuals who are highly active and participate in sports [34].

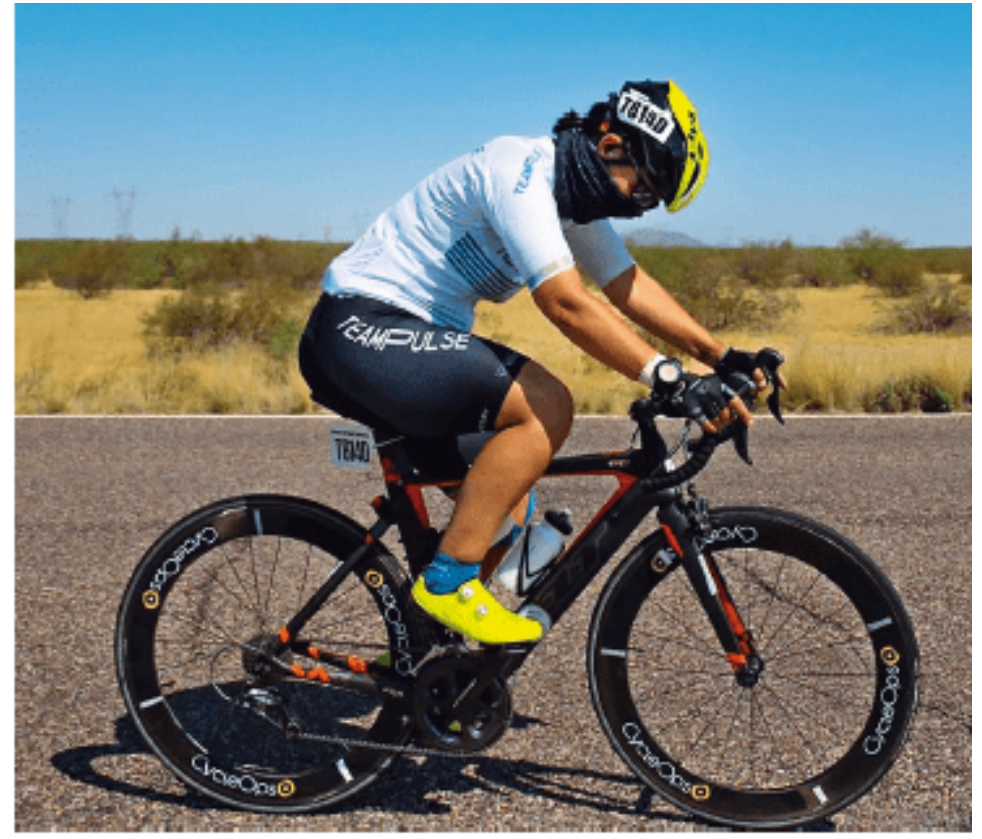

\section{Follow-up period}

At the end of the follow-up period, her physiological and psychological health parameters were comparable with data obtained following the institutional PA program. After some holydays, where BMI and BFM were increased, the main behavior change was observed: she bought a city bike for her daily mobility and practiced regularly two concurrent trainings per week in the fitness room of the University.

\section{Conclusion}

This case report shows that sedentary and physical inactive behaviors are not irreversible. Institutional PA program, including training education in addition to concurrent strength and endurance training could lead to physiological and psychological health improvements. Moreover, in some individuals organising a challenge might contribute to improve motivation and long-term adherence to PA participation, while in others this could have the opposite effect. An individualised approach should be considered in future interventions aiming to improve PA promotion. Finally, in the specific context of a University of Health Sciences, this kind of initiative could positively influence the general population's health, by educating students as actors in PA promotion. 


\section{Acknowledgement}

Authors would like to thank the School of Health Sciences for supporting the development of this project and the department of Sport Medicine of the Lausanne University Hospital for the physiological testing.

\section{Conflict of interest}

None declared

\section{Funding}

None declared

\section{Practical implications}

- Sedentary and physical inactive behaviors are not irreversible

- Institutional physical activity program, including concurrent strength and endurance training, and training education could lead to physiological and psychological health improvements

- Organising a challenge might contribute to improve motivation and long-term adherence to physical activity participation

\section{Corresponding author $\square$}

Kenny Guex

School of Health Sciences (HESAV),

HES-SO University of Applied Sciences

and Arts Western Switzerland,

Lausanne, Switzerland,

kenny.guex@hesav.ch,

+41213168046

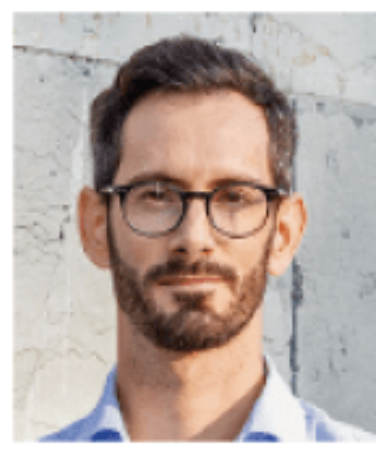

\section{References}

1. Matthews CE, Chen KY, Freedson PS, Buchowski MS, Beech BM, Pate RR, et al. Amount of time spent in sedentary behaviors in the United States, 2003-2004. Am J Epidemiol. 2008;167(7):875-81.

2. Sedentary Behaviour Research N. Letter to the editor: standardized use of the terms "sedentary" and "sedentary behaviours". Appl Physiol Nutr Metab. 2012;37(3):540-2.

3. Tremblay MS, Aubert S, Barnes JD, Saunders TJ, Carson V, Latimer-Cheung AE, et al. Sedentary Behavior Research Network (SBRN) - Terminology Consensus Project process and outcome. Int J Behav Nutr Phys Act. 2017;14(1):75.

4. Lee IM, Shiroma EJ, Lobelo F, Puska P, Blair SN, Katzmarzyk PT, et al. Effect of physical inactivity on 
major non-communicable diseases worldwide: an analysis of burden of disease and life expectancy. Lancet. 2012;380(9838):219-29.

5. Chau JY, Grunseit AC, Chey T, Stamatakis E, Brown WJ, Matthews CE, et al. Daily sitting time and allcause mortality: a meta-analysis. PLoS One. 2013;8(11):e80000.

6. WHO. Global recommendations on physical activity for health. Geneva, Switzerland: World Health Organization; 2010. p. 23-7.

7. Ekelund U, Steene-Johannessen J, Brown WJ, Fagerland MW, Owen N, Powell KE, et al. Does physical activity attenuate, or even eliminate, the detrimental association of sitting time with mortality? A harmonised meta-analysis of data from more than 1 million men and women. Lancet. 2016;388(10051):1302-10.

8. Rouse PC, Biddle SJH. An ecological momentary assessment of the physical activity and sedentary behaviour patterns of university students Health Educ J. 2010;69(1):116-25.

9. Peterson NE, Sirard JR, Kulbok PA, DeBoer MD, Erickson JM. Sedentary behavior and physical activity of young adult university students. Res Nurs Health. 2018;41(1):30-8.

10. Lehmann F, von Lindeman K, Klewer J, Kugler J. BMI, physical inactivity, cigarette and alcohol consumption in female nursing students: a 5-year comparison. BMC Med Educ. 2014;14:82.

11. Irazusta A, Gil S, Ruiz F, Gondra J, Jauregi A, Irazusta J, et al. Exercise, physical fitness, and dietary habits of first-year female nursing students. Biol Res Nurs. 2006;7(3):175-86.

12. McDowell N, McKenna J, Naylor PJ. Factors that influence practice nurses to promote physical activity. Br J Sports Med. 1997;31(4):308-13.

13. Shoak MA, Knechtle B, Knechtle P, Rust CA, Rosemann T, Lepers R. Participation and performance trends in ultracycling. Open access journal of sports medicine. 2013;4:41-51.

14. Zingg M, Knechtle B, Rust CA, Rosemann T, Lepers R. Age and gender difference in non-drafting ultraendurance cycling performance - the "Swiss Cycling Marathon”. Extrem Physiol Med. 2013;2(1):18.

15. Foster C. Monitoring training in athletes with reference to overtraining syndrome. Med Sci Sports Exerc. 1998;30(7):1164-8.

16. Foster C, Florhaug JA, Franklin J, Gottschall L, Hrovatin LA, Parker S, et al. A new approach to monitoring exercise training. J Strength Cond Res. 2001;15(1):109-15.

17. McGuigan MR, Foster C. A new approach to monitoring resistance training. Strength Cond J. 2004;26(6):42-7.

18. Day ML, McGuigan MR, Brice G, Foster C. Monitoring exercise intensity during resistance training using the session RPE scale. J Strength Cond Res. 2004;18(2):353-8.

19. Sweet TW, Foster C, McGuigan MR, Brice G. Quantitation of resistance training using the session rating of perceived exertion method. J Strength Cond Res. 2004;18(4):796-802.

20. ACSM. ACSM's guidelines for exercise testing and prescription. 9th ed. Philadelphia: Lippincott Williams \& Wilkins; 2014.

21. Craig CL, Marshall AL, Sjostrom M, Bauman AE, Booth ML, Ainsworth BE, et al. International physical activity questionnaire: 12-country reliability and validity. Med Sci Sports Exerc. 2003; 35(8):1381-95.

22. McNair DM, Lorr M, Droppleman LF. Revised manual for the Profile of Mood States. San Diego, CA: Educational and Industrial Testing Services; 1992.

23. Brière NM, Vallerand RJ, Blais MR, Pelletier LG. Développement et Validation d'une Mesure de Motivation Intrinsèque, Extrinsèque et d'Amotivation en Contexte Sportif: L'Échelle de Motivation dans les Sports (ÉMS). / Development and validation of a scale on intrinsic and extrinsic motivation and lack of motivation in sports: The Scale on Motivation in Sports. Int J Sport Psychol. 1995;26(4):465-89.

24. Gerovasili V, Agaku IT, Vardavas CI, Filippidis FT. Levels of physical activity among adults 18-64 years old in 28 European countries. Prev Med. 2015;81:87-91.

25. Murlasits Z, Kneffel Z, Thalib L. The physiological effects of concurrent strength and endurance 
training sequence: A systematic review and meta-analysis. J Sports Sci. 2018;36(11):1212-9.

26. Yusuf S, Hawken S, Ounpuu S, Bautista L, Franzosi MG, Commerford P, et al. Obesity and the risk of myocardial infarction in 27,000 participants from 52 countries: a case-control study. Lancet. 2005;366(9497):1640-9.

27. Michie S, van Stralen MM, West R. The behaviour change wheel: a new method for characterising and designing behaviour change interventions. Implement Sci. 2011;6:42.

28. Vellers HL, Kleeberger SR, Lightfoot JT. Inter-individual variation in adaptations to endurance and resistance exercise training: genetic approaches towards understanding a complex phenotype. Mamm Genome. 2018;29(1-2):48-62.

29. Bouchard C, Rankinen T. Individual differences in response to regular physical activity. Med Sci Sports Exerc. 2001;33(6 Suppl):S446-51; discussion S52-3.

30. Bouchard C. Genomic predictors of trainability. Experimental physiology. 2012;97(3):347-52.

31. O'Donovan G, Lee IM, Hamer M, Stamatakis E. Association of "Weekend Warrior" and Other Leisure Time Physical Activity Patterns With Risks for All-Cause, Cardiovascular Disease, and Cancer Mortality. JAMA Intern Med. 2017;177(3):335-42.

32. Goodman J, Thomas S, Burr JF. Physical activity series: cardiovascular risks of physical activity in apparently healthy individuals: risk evaluation for exercise clearance and prescription. Can Fam Physician. 2013;59(1):46-9,e6-e10.

33. Deliens T, Deforche B, De Bourdeaudhuij I, Clarys P. Determinants of physical activity and sedentary behaviour in university students: a qualitative study using focus group discussions. BMC Public Health. 2015;15:201.

34. Jago R, Anderson CB, Baranowski T, Watson K. Adolescent patterns of physical activity differences by gender, day, and time of day. Am J Prev Med. 2005;28(5):447-52. 